WEIGHT OF A FALLING DROP AND LAWS OF TATE. XVIr. $\quad 1845$

tain other cases, however, the results of Walden and Swinne were found to be from 2 to $4 \%$ higher than ours.

laboratory of Physical Chemistry,

NEW YORE CITY.

[CONTRIbutions from THE Chemical Laboratories OF COLUMbia UNTVERSTTY, No. 222.]

THE WEIGHT OF A FALLING DROP AND THE LAWS OF TATE, XVII. THE DROP WEIGHTS AND SURFACE TENSIONS OF MOLTEN HYDRATED SAITS, AND THEIR SOLUTIONS. ${ }^{1}$

By J. Livingston R. Morgan and EDward Scerasm. Received August 15, 1913.

In recent papers ${ }^{2}$ it has been shown, by the study of the drop weights of more than fifty normal or half-normal solutions, that the law proposed by Valson ${ }^{8}$ to the effect that equivalent solutions of various salts in water exhibit identical values for the surface tension is not true; for not only do the salts dissolved affect the surface tension of the solvent to a varying extent, but some even depress it. This conclusion has also been drawn by some of the best observers, employing (as did Valson) the capillary rise method; their results agreeing very closely with those calculated from the drop weight, wherever a comparison was possible.

The object of this paper is to present the results obtained by the study, not of many salts at the same concentration, but of many concentrations of a few salts. The molten hydrated salts selected for this purpose, i. e., those salts which melt below $50^{\circ}$ in their own water of crystallization being especially satisfactory for this purpose, for the reason that the concentration in some of the cases could even be carried to supersaturation.

Two tips were used in the course of the work, the constants for which were obtained from determinations of the drop weight of water by comparison with the surface tension of water, as found by Morgan and McAfee." At $30^{\circ}$, tip No. I gave an average weight of a drop of water of 77.700 milligrams, while tip No. 2 gave 77.472 from which we find $k_{\mathrm{B}_{\mathrm{z}}}=2.3134$ and $k_{\mathrm{B}_{2}}=2.3065$. To find the surface tension in dynes per centimeter from these tips, then we have the relations ${ }^{5}$

and

$$
\gamma=0.9 \mathrm{I}_{43} \times w_{1}
$$

$$
\gamma=0.9168 \times w_{2}
$$

Calcium Chloride Solutions.-Kahlbaum's purest $\mathrm{CaCl}_{2} 6 \mathrm{H}_{2} \mathrm{O}$ was

${ }^{1}$ For other papers of this series see reference, p. $182 \mathrm{I}$ in preceding article.

${ }^{2}$ Morgan and Bole, This Journal, 35, I750; and Morgan and MeKirahan, Fbid., $35, \mathbf{7 5 9}$.

${ }^{3}$ Compt. rend., 74, 103.

4 This Journal, 33, 1275-1290.

5 For details as to the standardization of a tip, see ThIs JourkaI, 33, I7 13-1727. 
used here, after being recrystallized several times by the freezing-out method. At first, these crystals were simply melted in their own water of crystallization and concentrated by heating until a strong supersaturated solution, not crystallizing out spontaneously at $30^{\circ}$, was obtained. A difficulty observed here at the very first was the absorption of water by this very hygroscopic liquid. In order to eliminate any effect of this, all results reported below were on liquids in which the concentration of salt was determined in the identical portion collected from the drops fallen and weighed. This weighed amount, contained in the stoppered weighing vessel was always immediately washed into a beaker and titrated with standard silver nitrate (standardized against specially purified sodium or potassium chloride).

One source of trouble with this, and with all other liquids of the type, was found in the fact that it wetted a glass surface only with the greatest of difficulty. This difficulty is certainly fatal in the case of the application of the capillary rise method, as there can be no possible way in which to make sure that the viscous liquid at any time is wetting the small capillary bore of the glass tube, as it should. With the drop-weight method, however, this can be determined readily, within fairly small limits, for very slight differences in the diameter of the tip covered by the liquid in the formation of the drop are evident to the eye. Invariably a lower value than usual could be predicted from the minute the liquid

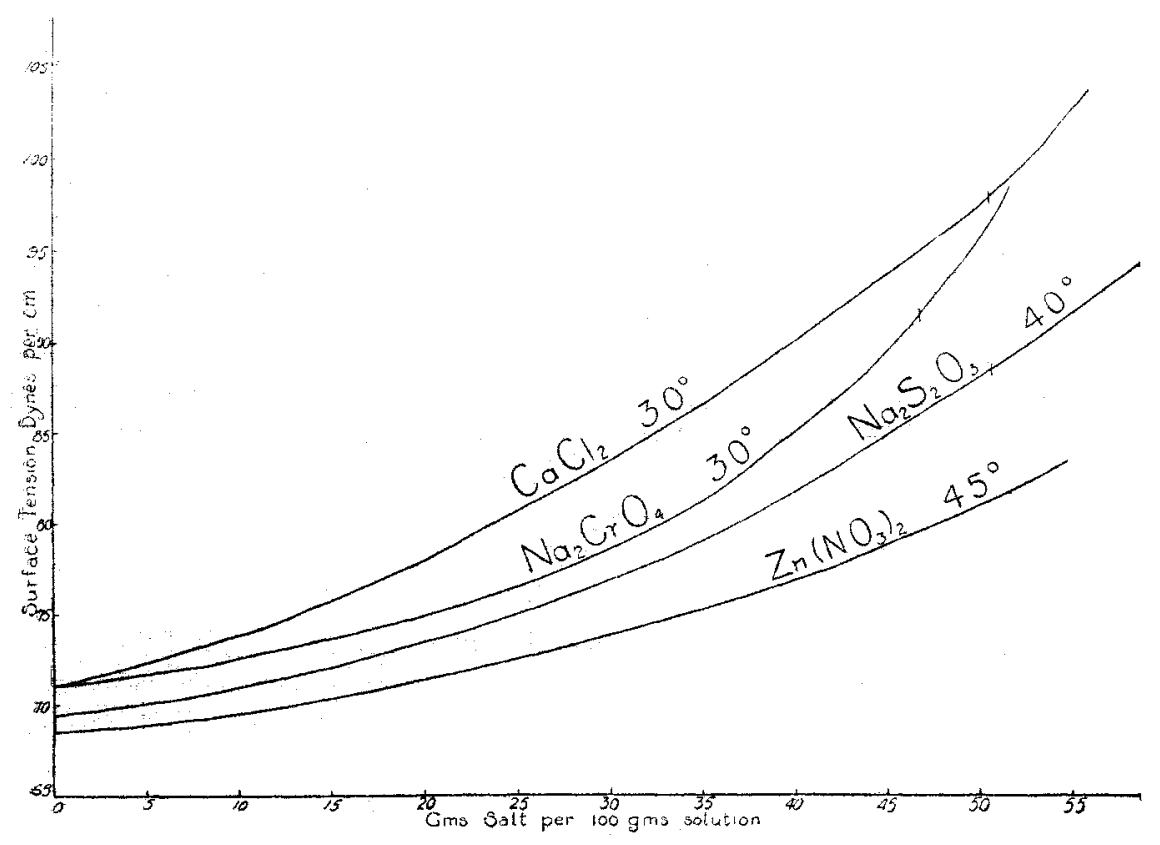

Fig. I. 
first ran out on the tip and wetted it. A very thorough cleansing of the tip was always necessary here, for without it the lack of covering power of the liquid on the tip was marked in all cases. The usual method was resorted to here, viz., chromic acid in hot diluted sulfuric acid, followed by pure water, the tip being then dried by a current of filtered, dried air.

There is no question here but that the capillary rise method will give much lower results by capillary ascension than the drop-weight method, owing to this lack of covering power of the liquid on glass. That was self-evident from the very beginning and was justified by the results obtained. Nor can there be any doubt that the drop-weight method gives the more correct results.

With the more concentrated solutions, the weight of five drops only was usually found, since the drops formed very slowly and were very heavy, so that the error was negligible. With the dilute solutions, as many as thirty drops were weighed. The vapor pressures of the stronger solutions were so small here that usually the determination of a blank to compensate for evaporation was unnecessary.

The results for drop weight found, and surface tension calculated by aid of the first of the above equations, are given below, some of the individual values being included to show about the limits of delicacy of the method applied to this case:

Calcium Chloride Solutions at $30^{\circ} \mathrm{C}$.

\begin{tabular}{|c|c|c|c|c|c|}
\hline Wt. 1 drop. & Av. & $\begin{array}{l}\text { Per cent. } \\
\text { CaCls. }\end{array}$ & $\begin{array}{l}\text { Mols } \mathrm{H}_{2} \mathrm{O} \\
\text { per mol } \\
\mathrm{CaCl}_{2}\end{array}$ & $\begin{array}{c}\text { Mols } \mathrm{CaCl}_{2} \\
\text { per } 1000 \mathrm{grams} \\
\mathrm{H}_{2} \mathrm{O} .\end{array}$ & $\begin{array}{c}\text { Surface } \\
\text { tension in } \\
\text { dyynes per cm }\end{array}$ \\
\hline 112.14$\}$ & $I \geq 2.20$ & 55.50 & 4.94 & II .24 & 102.57 \\
\hline $\begin{array}{l}112.26) \\
111.60\end{array}$ & III.60 & 54.76 & 5.09 & 10.91 & $\mathrm{IO2} 02$ \\
\hline 111.40$\}$ & & & & & \\
\hline 111.30$\}$ & I I I 35 & 54.65 & $5 \cdot 12$ & I0. 85 & IOI. 79 \\
\hline 111.00 & III. $\infty$ & 53.15 & 5.44 & 10.22 & 100.56 \\
\hline $\begin{array}{l}109.60 \\
108.90\end{array}$ & 109.60 & 53.04 & $5 \cdot 46$ & 10.18 & 100.19 \\
\hline 109.00 & 109.05 & 52,17 & 5.65 & 9.83 & 99.69 \\
\hline 109.24 & & & & & \\
\hline 108.60 & 108.60 & 5 I. 82 & $5 \cdot 73$ & 9.69 & 99.34 \\
\hline $\left.\begin{array}{l}108.30 \\
108.52\end{array}\right\}$ & $108.4 \mathrm{I}$ & $5 \mathrm{I} \cdot 40$ & 5.83 & 9.53 & 99. I0 \\
\hline $\left.\begin{array}{l}107.42 \\
107.26\end{array}\right\}$ & $107 \cdot 34$ & 50.66 & 6.01 & 9.25 & 98.12 \\
\hline $\left.\begin{array}{l}106.22 \\
106.12\end{array}\right\}$ & 106.17 & 49.46 & 6.18 & 9.00 & 97.06 \\
\hline $\left.\begin{array}{l}104.66 \\
104.92\end{array}\right\}$ & 104.79 & 48.65 & $6.5 \mathrm{I}$ & 8.53 & $95 \cdot 79$ \\
\hline $\left.\begin{array}{l}103.86 \\
103.90\end{array}\right\}$ & 103.88 & $47 \cdot 41$ & 6.84 & 8.12 & 94.96 \\
\hline
\end{tabular}


Calcium Chloride Solutions at $30^{\circ} \mathrm{C}$. (Continued).

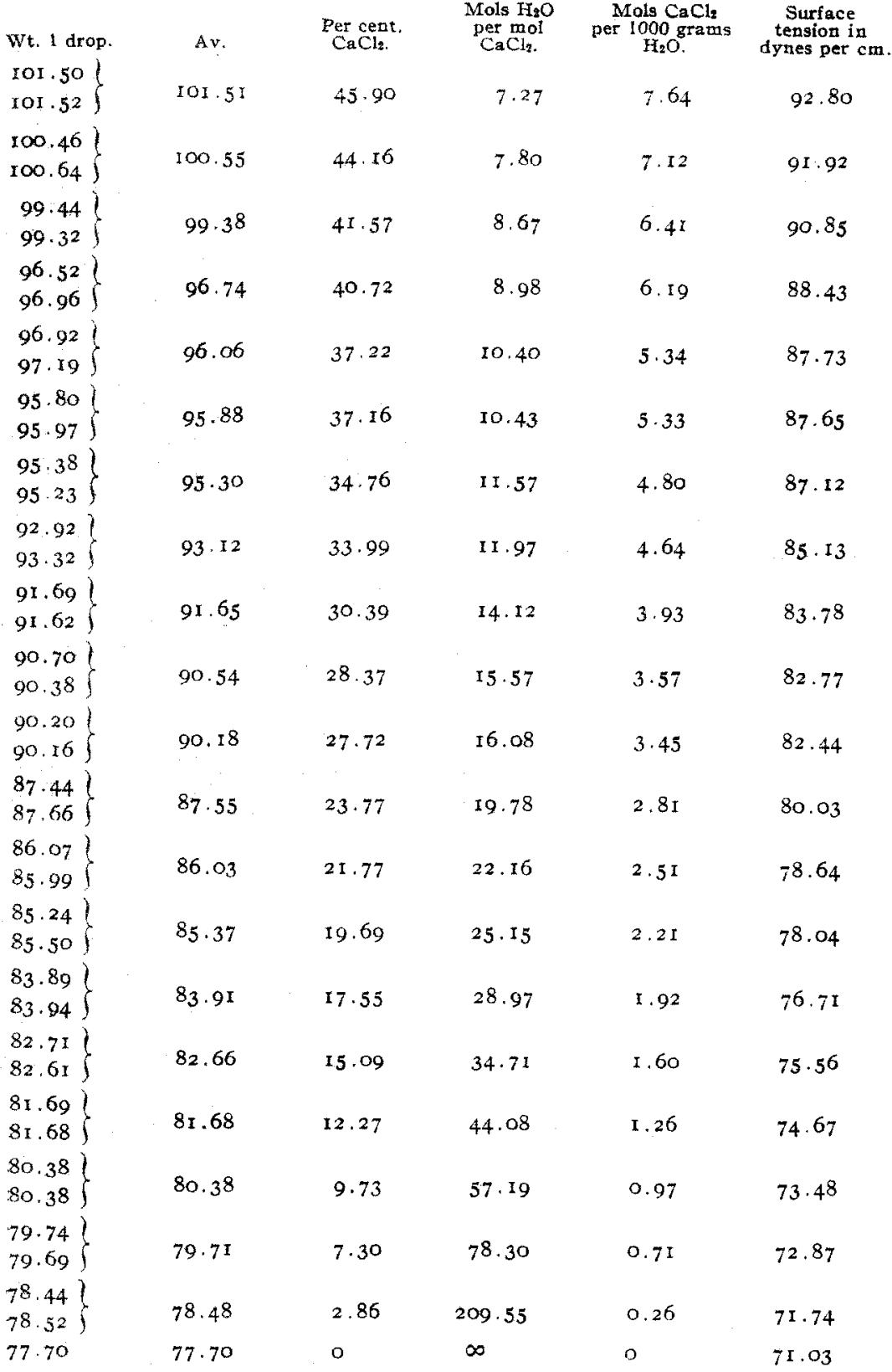

Zinc Nitrate Solutions.-Here the procedure was the same as with calcium chloride; but owing to the tendency of the strong solutions to 
crystallize spontaneously at the lower temperatures, all observations were made at $45^{\circ}$. The salt was from Kahlbaum, recrystallized. The analysis was made with a ferrocyanide titration in acetic acid solution. Tip 2 was used. The results for this liquid are given in the following table in a similar form to that used for the calcium chloride solutions:

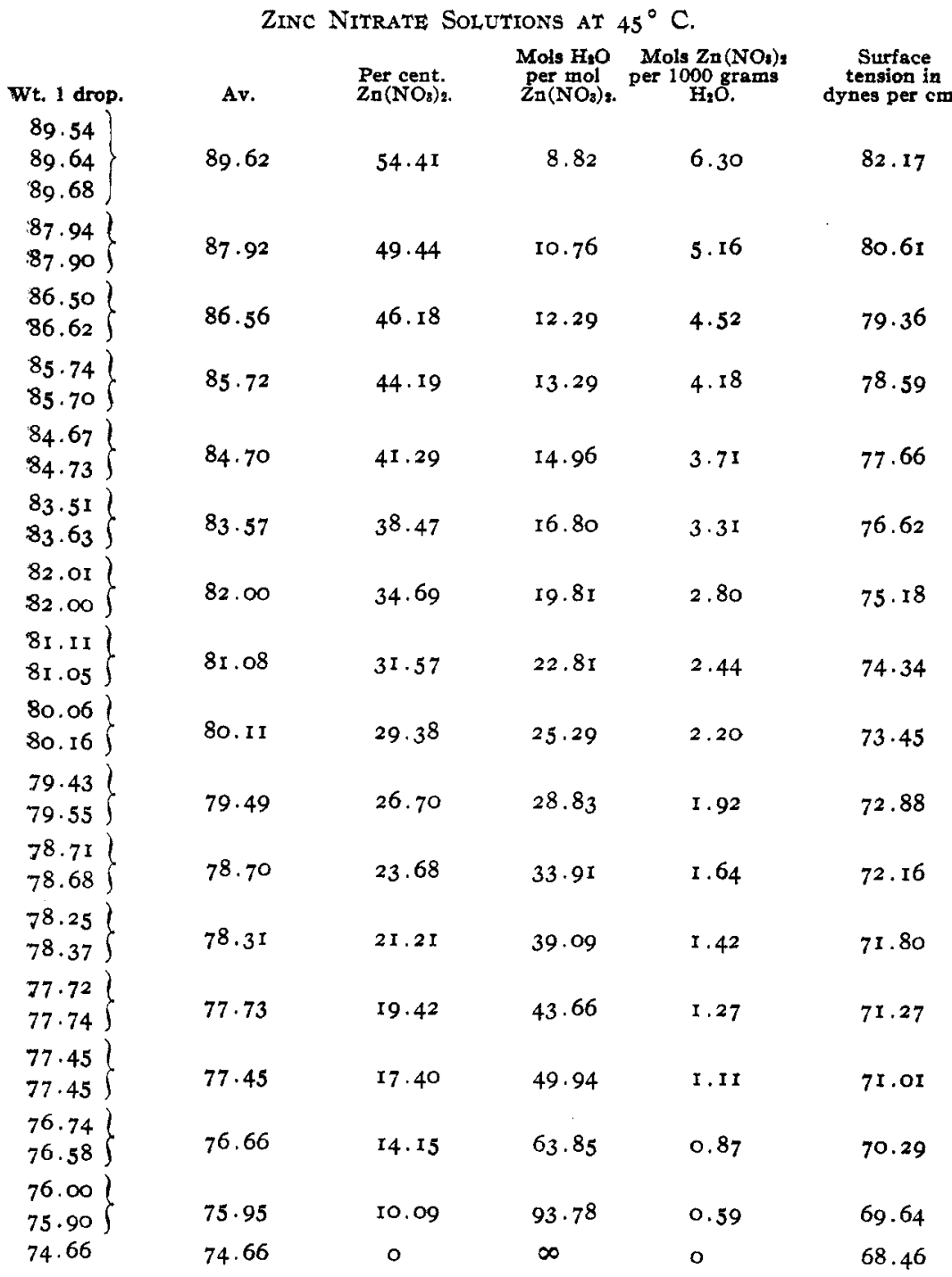

Sodium Chromate Solutions.-Here again, recrystallized Kahlbaum's salt was used, and the procedure was exactly as with the other two liquids. The analysis was accomplished by titrating the iodine, liberated from 
potassium iodide by the chromate in acid solution, with a solution of sodium thiosulfate which had been standardized against a known potassium dichromate solution. In this, and in the following case, the dilute solutions were made up with water by weight from the more concentrated ones. The results, determined and calculated, together with the concentrations in various forms are given below, Tip No. 2 being used.

Sodium Chromate Solutrons at $30^{\circ} \mathrm{C}$.

\begin{tabular}{|c|c|c|c|c|c|}
\hline $\left.\begin{array}{l}\text { Wt. 1 drop. } \\
106.06 \\
106.53\end{array}\right\}$ & 106.29 & $\begin{array}{l}\text { Per cent. } \\
\mathrm{Na}^{2} \mathrm{CrO}\end{array}$ & $\begin{array}{c}\text { Mols } \mathrm{H}_{2} \mathrm{O} \\
\text { per mol } \\
\mathrm{Na}_{2} \mathrm{CrO}_{4}\end{array}$ & $\begin{array}{c}\text { Mols } \mathrm{Na}_{2} \mathrm{CrO}_{4} \\
\text { per } 1000 \text { grams } \\
\mathrm{H}_{2} \mathrm{O} \text {. } \\
6.99\end{array}$ & $\begin{array}{c}\text { Surface } \\
\text { tension in } \\
\text { dynes per cru }\end{array}$ \\
\hline $\left.\begin{array}{l}104.04 \\
103.98\end{array}\right\}$ & 104.01 & $49.8 \mathrm{I}$ & 9.08 & 6.12 & $95 \cdot 36$ \\
\hline $\left.\begin{array}{l}\text { IOI } 14 \\
\text { IOI }, 02\end{array}\right\}$ & 101.08 & $47 \cdot 7^{2}$ & 9.87 & 5.63 & 92.68 \\
\hline $\left.\begin{array}{l}99.42 \\
99.64\end{array}\right\}$ & 99.53 & 46.78 & 10.25 & $5 \cdot 4^{2}$ & 91.26 \\
\hline $\left.\begin{array}{l}97.74 \\
98.00\end{array}\right\}$ & 97.87 & 45.25 & 10.90 & $5 \cdot 10$ & 89.73 \\
\hline $\left.\begin{array}{l}95.60 \\
95.86 \\
96.04\end{array}\right)$ & 95.83 & $43 \cdot 47$ & II .72 & 4.74 & 87.86 \\
\hline $\left.\begin{array}{l}92.46 \\
92.02\end{array}\right\}$ & 92.24 & 39.96 & $13 \cdot 54$ & $4 \cdot$ I I & 84.57 \\
\hline $\left.\begin{array}{l}88.74 \\
89.10 \\
88.90\end{array}\right\}$ & $88.9 \mathrm{I}$ & $34 \cdot 9$ I & 16.80 & 3.31 & $81.52-$ \\
\hline $\left.\begin{array}{l}85.94 \\
85.8 I\end{array}\right\}$ & 85.88 & 29.96 & 21.06 & 2.64 & 78.74 \\
\hline $\left.\begin{array}{l}83 \cdot 44 \\
83 \cdot 39\end{array}\right\}$ & 83.41 & 24.05 & 28.45 & I. 95 & $76.4^{8}$ \\
\hline $\left.\begin{array}{l}81,77 \\
8 \mathrm{I}, 76\end{array}\right\}$ & $81 \cdot 76$ & I9.35 & $37 \cdot 5^{6}$ & 1.48 & 74.96 \\
\hline $\left.\begin{array}{l}80.08 \\
80.04 \\
79.98 \\
79.92\end{array}\right\}$ & 80.00 & 12.67 & 62.10 & 0.89 & $73 \cdot 35$ \\
\hline $\left.\begin{array}{l}78.76 \\
78.69\end{array}\right\}$ & 78.72 & $7 \cdot 70$ & 108.05 & $0.5 I$ & 72.18 \\
\hline $\left.\begin{array}{l}78.15 \\
78.13\end{array}\right\}$ & 78.14 & $4 \cdot 45$ & 193.79 & 0.29 & 75.64 \\
\hline 77.47 & 77.47 & 0 & $\infty$ & 0 & 71.03 \\
\hline
\end{tabular}

Sodium Thiosulfate Solutions.-This specimen was from Eimer and Amend and was recrystallized several times before use by the freezing-out method. The concentration of the various solutions used was found by 
WEIGHT OF A FALLING DROP AND LAWS OF TATE. XVII. I85I

titration against an iodine solution that was re-standardized every other day against a known solution of sodium thiosulfate. This thiosulfate solution was tested at various times in the course of the work, but remained unchanged. The results, using Tip No. 2 are given below, a temperature of $40^{\circ}$ being used.

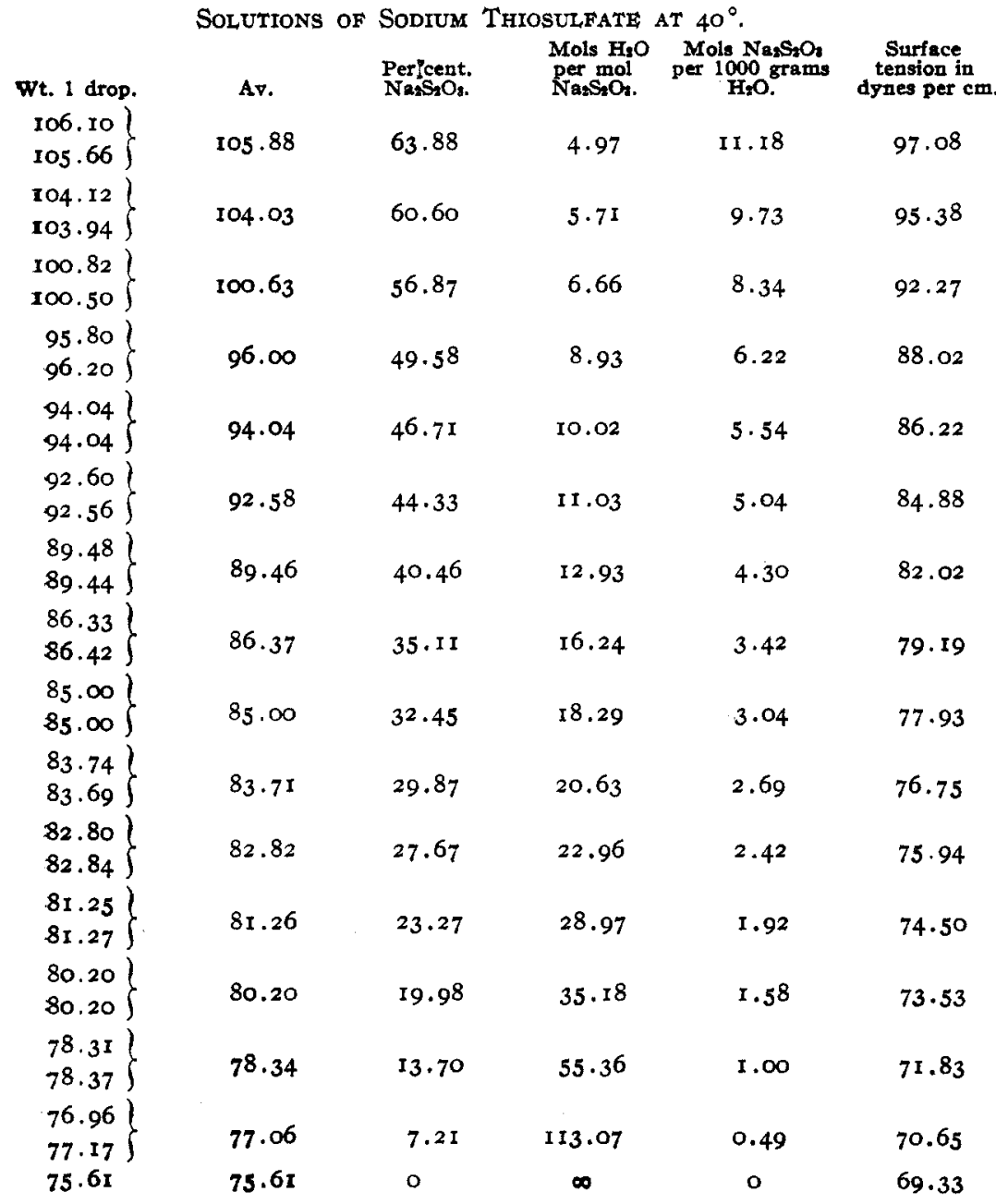

\section{Discussion of the Results.}

As will be noted, the results with these liquids did not check one another nearly as closely as is usual with the drop-weight method, probably on account of the lack of wetting or covering power, or perhaps we might say the small adhesion of the liquids to glass. The viscosity is probably not a factor at all, for, in previous papers, even more viscous liquids than 
these have been shown to lead to results agreeing well with the values obtained from capillary rise. As was to be expected, our results do not agree at all with those of high concentration to be found in the literature and found by the method based on capillary rise, and it seems certain. that our values are the more correct.

The best general idea of the results and their trend, can be obtained: from a glance at the curves representing them. It is interesting to observe: that there are no breaks to be found corresponding to saturated solutions, $i$. $e$, there is no discontinuity in surface tension in passing from stable solutions to unstable, supersaturated, solutions. In Fig. 2 the points

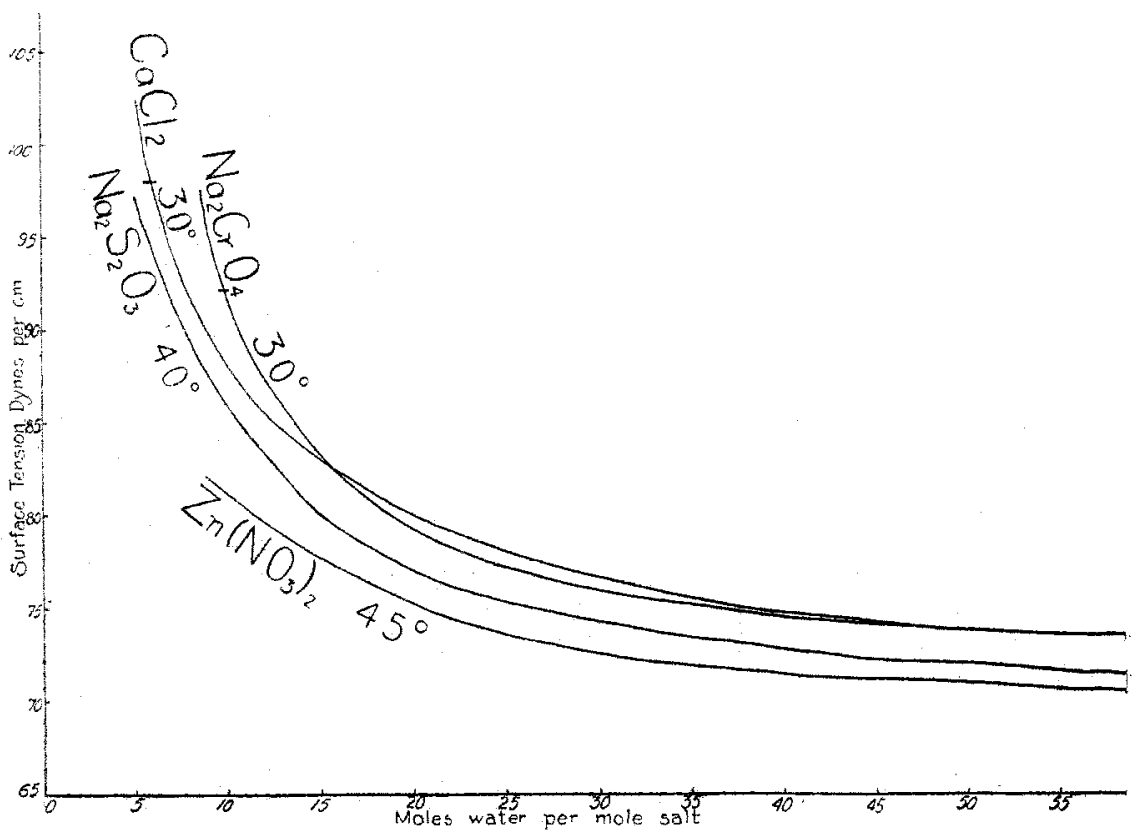

Fig. 2.

on the curve corresponding to recognized crystallin hydrates are marked. No change in direction seems present at these points. This may be taken to indicate that probably there is no definit, persistent, hydrate in solution corresponding to the crystallized solid. This would agree with the conclusions of Roozeboom ${ }^{1}$ and Lidbury ${ }^{2}$ on the freezing points of calcium chloride. Or it might also be taken to accord with the Jones theory that any hydration present in the solution varies progressively with the concentration.

A survey of the literature shows that, in general, investigators give a linear relationship as existing between surface tension and concentration

1 Z. physik. Chem., 4, 31.

2 Ibid, 39,459 . 
of salt in solution. It may be that this discrepancy between the results is due to the difficulty, alluded to above, caused by the relatively poor wetting power of the more concentrated solution. Our results, as will be seen, show this relationship to be plainly curvilinear, and a linear relationship only to be assumed for a very small change in concentration. Linebarger, ${ }^{1}$ however, came to this same conclusion by the aid of the capillary rise, when working with solutions of lithium, sodium and potassium chlorides, although Freundlich ${ }^{2}$ states that the curve for sodium chloride is nearly straight or slightly concave to the concentration axis. Our curves, as will be observed, as well as Linebarger's, are convex to the concentration axis.

From Fig. 2 it is evident that there is a decided germ of truth, qualitatively at any rate, in Valson's generalization that equivalent salt solutions exhibit identical values of the surface tension, even for the varied concentrations we have studied; for, if the change that would bring the thiosulfate and the nitrate down to the same temperature as the chloride and the chromate be made, it is evident that their curves would be raised so that, on the small scale of reproduction, they would seem almost to coincide with those for the chloride and chromate. This would mean that at the same number of mols or equivalents of any one of the four salts to the same number of mols of water, the surface tension would be the same within, say four or six per cent. Taking the law in this very approximate form, we can verify it. However, just as has already been shown, ${ }^{3}$ it certainly cannot be considered as more than a first approximation even, for our method is certainly accurate to within a few tenths of one per cent., even under the most unfavorable conditions. Contrasting Figs. I and 2 makes this very approximate relation more apparent, perhaps, than anything else; for the change in temperature would cause the curves very much more nearly to coincide in 2, where the concentration is expressed in mols, than in I where it is in grams (either per hundred grams of pure solvent, or in an equal amount of the solution). It may well be, perhaps, that this approximate law is only a portion, incorrectly expressed, of a very general and strictly quantitative law, which thus far has eluded formulation. That, however, is a question that only the future can answer.

Heydweiller ${ }^{4}$ has attempted to account for the influence of ionization upon the surface tension of aqueous solutions. From data, gathered from many different sources in the literature, he has selected what he considered as the most probable values. These he expressed in the form

1 ThIS JOURNAI, 2I, 4I5.

$$
\Delta=\operatorname{IOO} \frac{\gamma_{s}-\gamma_{w}}{m \gamma_{w}},
$$

2 Kapillarchemie, rgog, 61.

${ }^{3}$ Morgan and Bole; and Morgan and McKirahan.

${ }_{4}^{4}$ Ann. Phys., 33, 145. 
where $m$ is the number of gram equivalents of the salt per liter, and $\gamma_{w}$ and $\gamma_{s}$ were, respectively, the surface tension of water and solution at the same temperature. Therefore, $\Delta$ represents the percentage change in surface tension, produced by each equivalent per liter in the solution. This value, $\Delta$, he then placed equal to the effect of the ionized, and unionized portions of the salt, as well as to the total number of equivalents per liter of salt present, and obtained the following equation:

$$
\Delta=\mathrm{A} i+\mathrm{B}(\mathrm{r}-i)+\mathrm{C} m \text {. }
$$

Here $i$ is the percentage of ionization and $\mathrm{A}, \mathrm{B}$ and $\mathrm{C}$ are constants. From observed, or at least average values of $\Delta$, and Kohlrausch's value for $i$ (the ionization) he then found the values for the constants $A, B$ and $C$, and used them in other cases to calculate $\Delta$. The values of $\Delta$ which he calculated in general seem to agree very satisfactorily, so it was thought interesting to apply the equations to our consistent, high-concentration results.

For this purpose the figures for the density and ionization of sodium chromate, zinc nitrate, and calcium chloride solutions at $0^{\circ}$, were taken from the work of Jones. ${ }^{1}$ It was assumed here that $\gamma_{s}-\gamma_{w}$ would be practically the same at $0^{\circ}$ as at the temperature of observation; for previous work on solutions, in this series of papers, had shown the relationship of the changes in surface tension of both water and water solutions with the temperature to be linear, and that the graphs are practically parallel. The results of these calculations, giving only the final values, are contained in the following tables:

Calcium ChLORIDE.

$\begin{array}{ccr}m . & \Delta=100 \frac{\gamma_{s}-\gamma_{w}}{m \gamma_{w}} . & \Delta \text { calc. } \\ 0.051 & 7.75 & 8.22 \\ 0.076 & 7.63 & 8.03 \\ 0.102 & 7.62 & 7.60 \\ 0.127 & 7.58 & 7.60 \\ 0.153 & 7.49 & 6.77 \\ 0.204 & 7.24 & 7.13 \\ 0.255 & 7.08 & 7.40 \\ 0.306 & 7.11 & 7.26 \\ 0.500 & 7.43 & 6.98 \\ 0.750 & 7.98 & 7.68 \\ 1.000 & 8.38 & 8.59 \\ 1.137 & 8.74 & 8.98 \\ 1.299 & 9.10 & 9.38 \\ 1.461 & 9.21 & 10.28 \\ 1.624 & 9.47 & 11.09 \\ =12.39 ; B=-7.15 ; C=8.11\end{array}$

Zinc NITRATE.

\begin{tabular}{ccc}
$m$. & $\Delta=100 \frac{\gamma_{s}-\gamma_{w}}{m \gamma_{w}}$. & $\Delta$ calc. \\
0.032 & 4.95 & 4.95 \\
0.064 & 4.95 & 5.08 \\
0.129 & 4.70 & 5.45 \\
0.258 & 5.82 & 5.82 \\
0.645 & 6.17 & 6.47 \\
0.774 & 6.37 & 6.63 \\
0.903 & 6.55 & 6.70 \\
1.032 & 6.74 & 6.88 \\
1.290 & 6.99 & 6.99 \\
$\mathrm{~A}=3.80 ; \mathrm{B}=10.45 ; \mathrm{C}=-1.429$ \\
\multicolumn{3}{l}{}
\end{tabular}

1 Hydrates in aqueous solutions, Carnegie Inst. Pub. 60. 
WEIGHT OF A FALLING DROP AND LAWS OF TATE. XVII. $\quad$ I 855

Sodium Chromate.

$\begin{array}{ccc}m . & \Delta=100 \frac{\gamma_{S}-\gamma_{w}}{m \gamma_{w}} . & \Delta \text { calc. } \\ 0.025 & 4.2 \mathrm{I} & 4.12 \\ 0.050 & 4.48 & 4.46 \\ 0.100 & 4.88 & 4.89 \\ 0.150 & 5.18 & 5.11 \\ 0.200 & 5.60 & 5.32 \\ 0.250 & 5.64 & 5.5 \mathrm{I} \\ 0.300 & 6.02 & 5.72 \\ 0.400 & 6.16 & 6.16 \\ 0.500 & 6.46 & 6.42 \\ \mathrm{~A}=3.15 ; \mathrm{B}=8.05 ; \mathrm{C}=\mathrm{I.14}\end{array}$

There seems to be no agreement at all here in the case of calcium chloride, though to error in the calculation can be found, wike the agreement is occasionally : very remarkable in the other two cases: The results of this isolated test of Heydweiller's formula can not be sair to be conclusive in any way. Why calcium chloride should fail in it, while zinc nitrate and sodium chromate at times gives very good values, and at other times also fail slightly, is hard to see. Certainly it would seem that there are still other factors to consider. It may, of course, be possible that the surface tension-temperature graph of calcium chloride does not run parallel to that for water and those for the other solutions, so that our assumption that the value $\gamma_{s}-\gamma_{w}$ is the same at $0^{\circ}$ as at the temperature of our observation may not be justified in this one case.

\section{Summary.}

The results of this investigation may be summarized very briefly as follows:

I. The drop weights have been determined and the surface tensions calculated; for thirty-two concentrations of calcium chloride in water solution, for sixteen of zinc nitrate, for fourteen of sodium chromate, and for fifteen of sodium thiosulfate. It was found that supersaturated solutions behave, with respect to the surface tension, exactly as ordinary ones do.

2. The relationship between surface tension and concentration was in all cases found to be curvilinear, and convex to the concentration axis.

3. No change in curvature, which would indicate the presence of any hydrate in solution, was found in the curves.

4. Valson's relationship, namely, that salt solutions of equivalent concentration possess the same surface tension, was shown to be only approximately $(5-6 \%)$ true here with these four salts in solution, just as it has already been shown for more than fifty others in previous communications. It is pointed out, however, and shown plainly in the curves, that the equivalent strengths cause much more similarity in the value of surface tension 
than when the concentrations are the same with respect to numbers of grams.

5. Heydweiller's relationship, connecting the surface tension of solutions with the number of equivalents present and the ionization of the substance, was found to fail with our results in the case of calcium chloride, but at times to show up remarkably well with both zinc nitrate and sodium chromate.

LABORATORY OP PHystcal Chamitry.

[Contributions from the Chemical Iaboratories of Columbia University, No. 223.]

\section{THE WEIGHT OF A FALLING DROP ATD THE LAWS OF TATE, XVII. THE DROP WEIGHTS, SUDRACE TEMSIONS AND CAPILLARY COMSTANTS OF AQUROUS SOLUTIONS OF ETEYL, METAYL AND AMYL ALCOHOLS, AND OF ACETIC AND RORMIC ACID. ${ }^{1}$}

By J. Iivingston R. Morgan and Marrs NeIDteE. Received July 28, 1913.

In a previous paper ${ }^{2}$ it was shown that when the two non-associated liquids, benzene and carbon tetrachloride, were mixed together in equal parts by weight a critical temperature could be calculated for the mixture from the drop weight or surface tension, which was practically the mean of those of the two individual constituents; the only assumption made being that the density of the mixture is the mean of those of the two individual constituents. This can be shown in a more striking and direct way, and without any assumption at all, by calculating for each individual liquid an equation expressing the change of its surface tension, which is determined directly from drop weight, with the temperature, and taking the mean of the two. If the surface tension of the mixture, $I: I$, is then an additive property, this will be the equation giving its change with temperature. As Morgan and Thomssen worked at only one temperature, this calculated equation cannot be compared directly with an experimental one for the mixture; but a value from it can be calculated and then compared with the one value experimentally determined by them for the mixture. Proceeding in this way, we find that their results for the surface tensions of benzene and of carbon tetrachloride can be expressed by the equations $\gamma_{\mathrm{C}_{6} \mathrm{H}_{6}}=30.498-0.1305^{t}$ and $\gamma_{\mathrm{CCl}_{4}}=28.129-$ $0.15^{6} 6 t$, which, for a mixture of equal parts by weight would give $\gamma_{\text {mix. }}=$ $29.3 \mathrm{r} 4-0.123 \mathrm{It}$, as the mean equation of change with the temperature.

At $23.6^{\circ}$, Morgan and Thomssen find $\gamma_{\text {mix. }}=26.382$, whereas the above formula leads to the result $\gamma_{\text {mix. }}=26.409$; a difference of but 0.027 dynes, or $0.1 \%$.

IFor other papers of this series, see reference on p. 1821 .

2 Morgan and Thomssen, This JoURnaL, 33, 657--72 (1911). 